\title{
Hematological findings in coronavirus disease 2019: indications of progression of disease
}

\author{
Xiaoqing Liu ${ }^{1} \cdot$ Run Zhang ${ }^{1} \cdot$ Guangsheng $\mathrm{He}^{1}$ \\ Received: 3 May 2020 / Accepted: 21 May 2020 / Published online: 3 June 2020 \\ (C) Springer-Verlag GmbH Germany, part of Springer Nature 2020
}

\begin{abstract}
Coronavirus disease 2019 (COVID-19) is a new human infectious disease. The etiology for this outbreak is a novel coronavirus named severe acute respiratory syndrome coronavirus 2 (SARS-CoV-2). Thus far, related research on COVID-19 is still in preliminary stage. This paper summarized the latest outcomes of corresponding study from Chinese centers and clarified the hematopoietic abnormality caused by SARS-CoV-2 and potential mechanism. Lymphopenia was common in the early stage after the onset of COVID-19. A significant decrease was observed in peripheral CD4+ and CD8+ T lymphocytes. As the illness progressed, neutrophilia emerged in several cases, and patients with severe critical pulmonary conditions showed higher neutrophils than common type. Thrombocytopenia was resulting from the consumption and/or the reduced production of platelets in damaged lungs. Anemia was not observed notably, but the decrease in hemoglobin was frequent. The activation of monocytemacrophage system aggravates the immune damage of lung and other tissues, which leads to the increase of D-dimer, prothrombin time, and platelet consumption.
\end{abstract}

Keywords SARS-CoV-2 $\cdot$ COVID-19 $\cdot$ Lymphopenia $\cdot$ Neutrophilia $\cdot$ Thrombocytopenia $\cdot$ Hemoglobin

\section{Introduction}

Since December 2019, an increasing number of pneumonia cases of unknown reason emerged in Wuhan, China [1]. Deep-sequencing analysis from nasopharyngeal swabs, sputum, lower respiratory tract samples, and blood indicated a novel coronavirus, known as 2019-nCoV [2]. Coronavirus can cause multiple system infections and mainly respiratory infections in human, such as severe acute respiratory syndrome and Middle East respiratory syndrome [3-5]. The novel virus was named 2019 severe acute respiratory syndrome coronavirus 2 (SARS-CoV-2) by WHO; due to more than $79 \%$ homology with SARS-CoV, SARS-CoV-2 was responsible for coronavirus disease 2019 (COVID-19) [2]. At presentation, the number of cases increased rapidly, but related information regarding the clinical features and hematological changes of infected patients is limited [4-7].

Guangsheng He

heguangsheng1972@sina.com

1 Department of Hematology, the First Affiliated Hospital of Nanjing Medical University, Jiangsu Province Hospital, No. 300 Guangzhou Road, Nanjing 210029, Jiangsu, China
Initially reported clinical characteristics of COVID-19 mainly focused on inpatients, while a few SARS-CoV-2 infections may be with no or mild pneumonia-related symptoms, which belonged to the simple infection type in WHO classification [5-7]. Summarized COVID-19 cases including Hubei and other regions in China, common symptoms were consistent with the non-specific symptoms of acute respiratory infection [3-7]. Reported studies indicated the onset of inflammatory cytokine storms in COVID-19 leaded to progress to severe lung injury, respiratory distress, and multiple organ failure. Through literature analysis (most data from Chinese centers), we found that COVID-19 was prone to cause hematological changes (Table 1). Differences in hematological manifestations were detected between severe and non-severe patients. The severity of COVID-19 is defined according to the clinical management of severe acute respiratory infection when COVID-19 disease is suspected by WHO (version1.2) [2]. Severe illness is designated when the patients have fever or suspected respiratory infection, plus one of the following: respiratory rate $>30$ breaths/min; severe respiratory distress; or pulse oximeter oxygen saturation $\leq 93 \%$ on room air [2]. Critical illness is defined as patients with acute respiratory distress syndrome or sepsis with acute organ dysfunction [2]. Non-severe type represents patients with the exception 
Table 1 Comparisons of demographic and hematologic features between severe and non-severe COVID-19 patients

Variables References (case number) Reference value All patients

Disease severity

Non-severe patients $\quad$ Severe patients $\quad p$ value

Demographic characteristics

Age, median (IQR/range) or mean (SD), years

\begin{tabular}{|c|c|c|}
\hline $3(62)$ & NA & $41(32-52)$ \\
\hline 4 (1099) & NA & $47.0(35.0-58.0)$ \\
\hline $5(41)$ & NA & $49.0(41.0-58.0)$ \\
\hline $6(99)$ & NA & $55.5(21-82)$ \\
\hline 7 (138) & NA & $56(42-68)$ \\
\hline $11(201)$ & NA & $51(43-60)$ \\
\hline $15(33)$ & NA & NA \\
\hline $27(61)$ & NA & $40(1-86)$ \\
\hline $29(140)$ & NA & $57(25-87)$ \\
\hline $30(67)$ & NA & $42(35-54)$ \\
\hline
\end{tabular}

Male/female, No.

$3(62)$
$4(1099)$
$5(41)$
$6(99)$
$7(138)$
$11(201)$
$15(33)$
$27(61)$
$29(140)$
$30(67)$

$\begin{array}{ll} & 36 / 27 \\ \text { NA } & 640 / 459 \\ \text { NA } & 30 / 11 \\ \text { NA } & 67 / 32 \\ \text { NA } & 75 / 63 \\ \text { NA } & 128 / 73 \\ \text { NA } & \text { NA } \\ \text { NA } & 31 / 30 \\ \text { NA } & 71 / 69 \\ \text { NA } & 37 / 30\end{array}$

Blood laboratory findings*

Lymphocyte count, median (IQR), $\times 10^{9} / \mathrm{L}$

$$
\begin{aligned}
& 3(62) \\
& 4(1099) \\
& 5(41) \\
& 7(138) \\
& 11(201) \\
& 15(33) \\
& 27(61) \\
& 29(140) \\
& 30(67)
\end{aligned}
$$

$\begin{array}{ll}0.8-4.0 & 1.0(0.8-1.5) \\ \text { NA } & 1.0(0.7-1.3) \\ \text { NA } & 0.8(0.6-1.1) \\ 1.1-3.2 & 0.8(0.6-1.1) \\ 1.1-3.2 & 0.91(0.60-1.29) \\ \text { NA } & \text { NA } \\ \text { NA } & 1.0(0.8-1.4) \\ 1.1-3.2 & 0.8(0.6-1.1) \\ \text { NA } & 1.2(0.8-1.6)\end{array}$

Lymphopenia, No./total No. (\%)

$$
\begin{aligned}
& 3(62) \\
& 4(1099) \\
& 5(41) \\
& 6(99) \\
& 11(201) \\
& 29(140) \\
& 30(67)
\end{aligned}
$$

$\mathrm{CD} 3, / \mu \mathrm{L} \quad 11(201)$

$\mathrm{CD} 4, / \mu \mathrm{L} \quad 11(201)$

$\mathrm{CD} 8, / \mu \mathrm{L} \quad 11(201)$

\begin{tabular}{ll}
\multicolumn{1}{r}{$<1.0$} & $26 / 62(42)$ \\
$<1.5$ & $731 / 890(82.1)$ \\
$<1.0$ & $26 / 41(63)$ \\
$<1.1$ & $35 / 99(35)$ \\
$<1.1$ & $126 / 197(64.0)$ \\
$<1.1$ & $104 / 138(75.4)$ \\
NA & $24 / 65(36.9)$ \\
$\quad$ NA & $607.00(430.50-8$ \\
$\quad$ NA & $353.00(226.50-4$ \\
$\quad$ NA & $236.00(142.50-3$ \\
L & \\
$\quad 2-7$ & $2.9(2.0-3.7)$ \\
NA & $5.0(3.3-8.9)$ \\
$1.8-6.3$ & $3.0(2.0-4.9)$ \\
$1.8-6.3$ & $4.47(2.32-7.70)$ \\
NA & NA \\
NA & $2.6(2.1-4.1)$
\end{tabular}

Neutrophilia, No./total No. (\%)

$$
\begin{aligned}
& 6(99) \\
& 11(201)
\end{aligned}
$$

$38 / 99$ (38)

68/197 (34.5)

$\begin{array}{ll}>6.3 & 38 / 99(38) \\ >6.3 & 68 / 197(34.5)\end{array}$

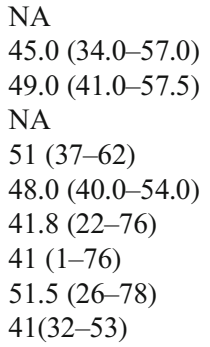

NA

$45.0(34.0-57.0)$

$49.0(41.0-57.5)$

NA

$51(37-62)$

$48.0(40.0-54.0)$

$41.8(22-76)$

$41(1-76)$

$51.5(26-78)$

$41(32-53)$

NA
$540 / 386$
$19 / 9$
NA
$53 / 51$
$68 / 49$
$13 / 8$
$21 / 23$
$38 / 44$
$31 / 27$

\section{NA}

$1.0(0.8-1.4)$

$1.0(0.7-1.1)$

$0.9(0.6-1.2)$

$1.08(0.72-1.45)$

$1.33(0.28-2.86)$

$1.1(0.9-1.4)$

$0.8(0.6-1.2)$

$1.3(0.9-1.7)$

NA
$584 / 736(79.3)$
$15 / 28(54)$
NA
NA
$58 / 82(70.7)$

$17 / 56(30.4)$

$633.00(467.00-846.00)$

$371.00(283.00-572.00)$

$241.00(159.00-323.00)$
NA
$4.4(2.0-6.1)$
$2.7(1.9-3.9)$
$3.06(2.03-5.56)$
$3.36(1.37-10.03)$
$2.6(2.1-3.8)$

NA

NA

$52.0(40.0-65.0)$

$49.0(41.0-61.0)$

NA

66 (57-78)

$58.5(50.0-69.0)$

50(29-68)

$56(34-73)$

64 (25-87)

54(47-62)

value 
Table 1 (continued)

Variables References (case number) Reference value All patients

tall patients

NLR $27(61)$

Leukocytosis, No./total No. (\%)

$\begin{array}{ll}5(41) & >10 \\ 6(99) & >9.5 \\ 11(201) & >9.5 \\ 29(140) & >9.5 \\ \text { unt, median (IQR), } \times 10^{9} / \mathrm{L} & \\ 3(62) & 83-303 \\ 4(1099) & \text { NA } \\ 5(41) & \text { NA } \\ 7(138) & 125-350 \\ 11(201) & 125-350 \\ 15(33) & \text { NA } \\ 27(61) & \text { NA } \\ 30(67) & \text { NA }\end{array}$

Thrombocytopenia, No./total No. (\%)

$\begin{array}{ll}3(62) & <83 \\ 4(1099) & <150 \\ 5(41) & <100 \\ 6(99) & <125 \\ 11(201) & <125\end{array}$

Hemoglobin level, median (IQR) or mean (SD), g/L

$\begin{array}{lll}3(62) & 113-151 & 137.0(128.8-152.3) \\ 4(1099) & \text { NA } & 134.0(119.0-148.0) \\ 5(41) & \text { NA } & 126.0(118.0-140.0) \\ 6(99) & 130-175 & 129.8(14.8) \\ 15(33) & \text { NA } & \text { NA } \\ 27(61) & \text { NA } & 138.0(127.0-150.5) \\ 30(67) & \text { NA } & 140(129-152)\end{array}$

$12 / 40(30)$
$24 / 99(24)$
$46 / 197(23.4)$
$17 / 138(12.3)$
$176.0(135.8-215.5)$
$168.0(132.0-207.0)$
$164.5(131.5-263.0)$
$163(123-191)$
$180.00(137.00-241.50)$
NA
$164.0(135.0-219.5)$
$201(155-263)$

$3 / 62(5)$
$315 / 869(36.2)$
$2 / 40(5)$
$12 / 99(12)$
$37 / 197(18.8)$

$\begin{array}{lll}\text { median }(\mathrm{IQR}) \text { or mean }(\mathrm{SD}), \mathrm{mg} / \mathrm{L} & \\ 3(62) & 0-0.7 & 0.2(0.2-0.5) \\ 5(41) & \mathrm{NA} & 0.5(0.3-1.3) \\ 6(99) & 0-1.5 & 0.9(0.5-2.8) \\ 7(138) & 0-500 & 203(121-403) \\ 11(201) & 0-1.5 & 0.61(0.35-1.28) \\ 15(33) & \mathrm{NA} & \mathrm{NA} \\ 29(140) & 0-0.243 & 0.2(0.1-0.5)\end{array}$

D-dimer increased, No./total No. (\%)

$\begin{array}{lll}4(1099) & \geq 0.5 & 260 / 560(46.4) \\ 6(99) & >1.5 & 36 / 99(36) \\ 11(201) & >1.5 & 44 / 189(23.3) \\ 29(140) & >0.243 & 35 / 81(43.2)\end{array}$

Prothrombin time, median (IQR) or mean (SD), s

\begin{tabular}{lll}
$5(41)$ & \multicolumn{1}{c}{ NA } & $11.1(10.1-12.4)$ \\
$6(99)$ & $10.5-13.5$ & $11.3(1.9)$ \\
$7(138)$ & $9.4-12.5$ & $13.0(12.3-13.7)$ \\
$11(201)$ & $10.5-13.5$ & $11.10(10.20-11.90)$ \\
$15(33)$ & NA & NA \\
$27(61)$ & NA & $12.0(11.1-13.1)$
\end{tabular}

Disease severity

\begin{tabular}{lll}
\hline Non-severe patients & Severe patients & $p$ value \\
\hline $2.2(1.4-3.1)$ & $3.6(2.5-5.4)$ & 0.003 \\
& & \\
$5 / 27(19)$ & $7 / 13(54)$ & NA \\
NA & NA & NA \\
NA & NA & NA \\
$4 / 82(4.9)$ & $13 / 56(23.2)$ & 0.003
\end{tabular}

$\begin{array}{lll}\text { NA } & \text { NA } & \text { NA } \\ 172.0(139.0-212.0) & 137.5(99.0-179.5) & <0.001 \\ 149.0(131.0-263.0) & 196.0(165.0-263.0) & 0.45 \\ 165(125-188) & 142(119-202) & 0.78 \\ 178.00(140.00-239.50) & 187.00(124.50-252.50) & 0.73 \\ 184.88(131-292) & 194.58(72-307) & 0.64 \\ 167.5(151.0-219.8) & 153.0(120.5-216.0) & 0.347 \\ 201(157-263) & 217(154-301) & 0.81 \\ & & \\ \text { NA } & \text { NA } & \text { NA } \\ 225 / 713(31.6) & 90 / 156(57.7) & <0.001 \\ 1 / 27(4) & 1 / 13(8) & 0.45 \\ \text { NA } & \text { NA } & \text { NA } \\ \text { NA } & \text { NA } & \text { NA }\end{array}$

\section{NA}

$135.0(120.0-148.0)$

$130.5(120.0-140.0)$ NA

145.24111-162)

139.0 (126.5-151.8)

142(129-152)

128.0 (111.8-141.0)

NA

$<0.001$

0.20

NA

0.002

0.797

0.07
NA 122.0 (111.0-128.0) NA

125.42 (97-144)

$138.0(127.5-148.0)$ 132(125-140)

NA

$2.4(0.6-14.4)$

NA

414 (191-1324)

$1.16(0.46-5.37)$

$0.61(0.08-3.93)$

$0.4(0.2-2.4)$

65/109 (59.6)

NA

NA

$23 / 38(60.5)$

$195 / 451(43.2)$
NA
NA
$12 / 43(27.9)$

10.7 (9.8-12.1)

NA

$12.9(12.3-13.4)$

$10.60(10.10-11.50)$

21.08 (12.1-142)

$12.0(10.8-13.1)$

$\begin{array}{ll}12.2(11.2-13.4) & 0.012 \\ \text { NA } & \text { NA } \\ 13.2(12.3-14.5) & 0.37 \\ 11.70(11.10-12.45) & <0.001 \\ 14.23(12.7-15.3) & 0.46 \\ 12.0(11.7-12.6) & 0.729\end{array}$

NA

0.0042

NA

$<0.001$

$<0.001$

0.09

$<0.001$

0.003

NA

NA

0.004

0.012

$<0.001$

0.729

$I Q R$, interquartile range; $S D$, standard deviation; $N A$, not available; $N L R$ : neutrophil-to-lymphocyte ratio

*All hematologic abnormalities were determined according to the relevant reference 
of the above conditions [2].A blood workup as well as continuous tracking hematological changes could reveal the risks of disease progression.

\section{Hematological findings in COVID-19 patients}

\section{Lymphopenia}

Lymphopenia generally occurs with leukopenia after coronavirus infection, even white blood cell count remains in normal range. The initial blood count showed moderate lymphopenia $\left(<1.0 \times 10^{9} / \mathrm{L}\right)$ in $69.6 \%$ cases with SARS, and $33.9 \%$ of the patients had leukopenia $\left(<3.5 \times 10^{9} / \mathrm{L}\right)$, whereas the neutrophil count and the monocyte count were mostly normal [8]. A study of 157 patients with SARS demonstrated that lymphopenia $\left(<1.0 \times 10^{9} / \mathrm{L}\right)$ was noted in $98 \%$ during their course of disease, and temporary leukopenia was detected in $64 \%$ of patients in the first week of illness [9]. The first case of SARS-CoV-2 infection confirmed in the USA developed a slight decrease in white cell count within 1 week from onset [10]. An early research of 41 patients with COVID-19 hospitalized at Jin Yin-tan Hospital showed that the blood counts of them on admission indicated leukopenia (accounted for 25\%) and lymphopenia (accounted for 63\%) [5]. Subsequently, in a larger sample study, only 9\% of COVID-19 cases showed decreased leukocyte, while the proportion of lymphopenia was still as high as 35\% [6]. Zhongnan Hospital of Wuhan University reported clinical features of 138 patients with COVID-19 and found that up to $70.3 \%$ of them developed lymphopenia with a median lymphocyte count of $0.8 \times 10^{9}$ / L [7]. Of the 140 COVID-19 patients with blood cell test on the day of hospital admission, $75.4 \%$ of them showed lymphopenia [11]. A latest domestic research extracted the data of 1099 cases with laboratory-confirmed COVID-19 from 552 hospitals in 31 provinces/provincial municipalities in China, of which $33.7 \%$ had leukopenia $\left(<4.0 \times 10^{9} / \mathrm{L}\right)$ and $82.1 \%$ had lymphopenia $\left(<1.5 \times 10^{9} / \mathrm{L}\right)[4]$. Another retrospective cohort study summarized the initial laboratory indices of patients with COVID-19 and proposed that more than half of them had lymphopenia (126 of 197, 64\%) [12]. Lymphocytes, the major antiviral cells, were found to be prone to decrease continually and severely in ICU and dead patients when Zhongnan Hospital of Wuhan University kept track of the lymphocyte changes in COVID-19 patients [7]. Compared with patients without acute respiratory distress syndrome (ARDS), for patients with ARDS, the value of lymphocyte counts (difference, $-0.34 \times 10^{9} / \mathrm{mL} ; 95 \% \mathrm{CI},-0.47$ to $-0.22 \times 10^{9} / \mathrm{mL}$; $p<0.001$ ), $\mathrm{CD}^{+}$(difference, -138.00 cells $/ \mu \mathrm{L} ; 95 \% \mathrm{CI},-$ 224.00 to -51.00 cells $/ \mu \mathrm{L} ; p=0.004$ ), and $\mathrm{CD}^{+} \mathrm{T}$ cells (difference, -66.00 cells $/ \mu \mathrm{L} ; 95 \% \mathrm{CI},-129.00$ to -7.00 cells $/ \mu \mathrm{L}$; $p=0.03$ ) were significantly decreased [12]. In the first COVID19 case reported in the USA, improvement in infection-related symptoms and recovery in lymphocyte occurred almost simultaneously (about 2 weeks of illness) [10]. Peripheral blood lymphocyte count $<0.8 \times 10^{9} / \mathrm{L}$ was entered in a backward stepwise logistic regression analysis to predict the mortality of virus-infected pneumonia patients $(\mathrm{OR}=4.53,95 \%$ CI 2.55 $8.05, p<0.001)$ [13]. The median lymphocyte count of early reported COVID-19 cases was $0.8 \times 10^{9} / \mathrm{L}$, demonstrating a high proportion of severe cases or a high risk of course progression among hospitalized patients in Wuhan [5, 7].

The counts of $\mathrm{CD}^{+}$and $\mathrm{CD} 8^{+} \mathrm{T}$ cells fell early during the course of SARS, which was associated with adverse outcomes [9]. In patients infected with cytomegalovirus (CMV) and Epstein-Barr virus (EBV), the $\mathrm{CD} 8^{+} \mathrm{T}$ lymphocytes increased remarkably, but $\mathrm{CD}^{+} \mathrm{T}$ cells did not show a significant change compared with normal controls [14]. For human immunodeficiency virus (HIV) infection, $\mathrm{CD} 4^{+} \mathrm{T}$ cells dropped quickly and returned to normal range in the acute phase, while $\mathrm{CD}^{+} \mathrm{T}$ cells were prone to elevate and remain at a high level for several years [14]. In SARS cases, both $\mathrm{CD}^{+}$and $\mathrm{CD} 8^{+} \mathrm{T}$ lymphocytes declined, of which the absolute count decreased seriously than EBV, CMV, and HIV infection [14]. Lung injury model of SARS-CoV in BALB/c mice revealed the rapid kinetics of SARS-CoV replication and relative delayed type I interferon (IFN-I) expression in lungs resulting in the accumulation of pathogenic inflammatory monocyte-macrophages (IMMs), elevation of lung cytokine/chemokine levels, and vascular leakage [15]. In addition, IFN-I sensitized virusspecific $\mathrm{T}$ cell $\left(\mathrm{CD}^{+}\right.$and $\left.\mathrm{CD} 8^{+}\right)$to apoptosis by upregulating Fas and Fas ligand on T cells [15].

It was manifested that the $\mathrm{CD} 4^{+} \mathrm{T}$ lymphocytes were rapidly activated to be Thelper (Th) 1 cells and induced inflammatory CD14 CD16 monocytes with high expression of interleukin-6 (IL-6) and accelerated the inflammation [16]. Importantly, high percentage of co-expression Tim- $3^{+} \mathrm{PD}-1^{+}$ $\mathrm{T}$ subset existed both in $\mathrm{CD} 4^{+}$and $\mathrm{CD} 8^{+} \mathrm{T}$ lymphocytes, especially in ICU patients, which suggested $\mathrm{T}$ cells were in exhausted status from activation [16-18]. The peripheral blood from a dead COVID-19 patients was detected by flow cytometric and found that the counts of CD4+ and CD8+ T lymphocytes were decreased, while the proportion of HLADR (CD4, 3.47\%) and CD38 (CD8, 39.4\%) double-positive fraction was high, indicating the hyperactivated status of $\mathrm{T}$ cells [19]. Besides that, an elevated concentration of proinflammatory $\mathrm{CCR} 4^{+} \mathrm{CCR} 6^{+} \mathrm{Th} 17$ was found in $\mathrm{CD} 4^{+} \mathrm{T}$ cells and high expressions of cytotoxic granules in $\mathrm{CD} 8^{+} \mathrm{T}$ cells (31.6\% cells were perforin positive, $64.2 \%$ cells were granulysin positive, and $30.5 \%$ cells were double positive), which all proved the overactivation of T lymphocytes [19].

ACE2 (angiotensin converting enzyme 2) acts as the receptor to infect cells for both SARS-CoV-2 and SARS-CoV [20, 21]. $\mathrm{ACE}$ and $\mathrm{ACE} 2$ are homologues with different functions in the renin-angiotensin system (RAS), regulating blood pressure, vascular resistance, and the balance of fluid and electrolyte [22]. 
ACE2 negatively regulates RAS by inactivating angiotensin II (Ang II), which derived from decapeptide angiotensin I (Ang I) under the action of ACE [23]. The mouse models of acute lung injury showed that ACE2 knockout mice displayed more severe symptoms and the overexpression of ACE2 possessed protective function [24]. In mice infected with SARS-CoV, viral replication and viral spike protein were confirmed that could selectively reduce ACE2 but not ACE expression, and severe lung injury was mainly caused by high levels of Ang II due to the reduced ACE2 [24, 25].

A variety of studies has shown a possible role of ACE in regulating aspects of hematopoiesis [26]. It was demonstrated that increased expression of ACE in myeloid cells facilitated myeloid maturation and skewed myeloid differentiation to a more pro-inflammatory phenotype (myelomonocytic cells and macrophages), inhibited the development of myeloidderived suppressor cells (MDSCs) in a tumor model and in a model of chronic inflammation induced by complete Freund's adjuvant [27].

It could be proposed that SARS-CoV-2 infection resulted in reduction of ACE2 and increased expression of ACE in myeloid precursors, which potentially facilitated myeloid maturation and made macrophages more pro-inflammatory along with reduction of the generation of MDSCs, and activated T cells, subsequently worsen immune response of target cells and consumption of T cells, especially CD4 and CD8 T cells. Furthermore, the pro-inflammatory phenotype of macrophage causes severe immune damage to the lung and other organs.

\section{Neutrophilia}

A series of COVID-19 reports suggested that ICU cases were more likely to appear neutrophilia, which is an indicator associated with disease progression $[5,7,28]$. According to the data from Jin Yin-tan Hospital, the median absolute neutrophil count (ANC) in ICU cases was $10.6(5.0-11.8) \times 10^{9} / \mathrm{L}$, much higher than the $4.4(2.0-6.1) \times 10^{9} / \mathrm{L}$ in non-ICU cases $(p=$ 0.00069 ) [5]. The median ANC of ICU and non-ICU patients with COVID-19 in the report of Zhongnan Hospital of Wuhan University was $4.6(2.6-7.9) \times 10^{9} / \mathrm{L}$ and $2.7(1.9-3.9) \times 10^{9} /$ L, respectively [7]. Similar results were found in the study from Beijing Ditan Hospital; the median neutrophil count of common type was $2.4(1.9-3.4) \times 10^{9} / \mathrm{L}$, while the median neutrophil was higher in severe or critical type, 2.8 (2.3$4.4) \times 10^{9} / \mathrm{L},(p=0.025)$ [28]. A study of 69 confirmed cases of SARS-CoV-2 infection from Singapore showed that ICU patients tend to develop neutrophilia during hospitalization with a median peak ANC of $11.6 \times 10^{9} / \mathrm{L}$, compared to $3.5 \times$ $10^{9} / \mathrm{L}$ in the non-ICU group [29]. According to a retrospective research including initial laboratory indices of COVID-19 patients, $34.5 \%$ of them demonstrated neutrophilia, and patients with ARDS (7.04, (IQR 3.98 to 10.12)) developed higher neutrophils than those without ARDS (3.06, (IQR 2.03 to
5.56)), $(p<0.001)$ [12]. Furthermore, among patients with ARDS, higher neutrophils were detected in those who had died [12]. Hematological parameters were tracked from day 1 to day 19 after the onset of COVID-19 at an interval of 2 days, and it was found that non-survivors developed more severe lymphocytopenia and higher neutrophils counts than survivors [7].

Risk factors associated with the composite endpoint (included admission to ICU, requirement of invasive ventilation and death) in univariate competing risk model suggested that leukocyte count more than $4000 / \mathrm{mm}^{3}$ was a related indicator (hazards ratio, HR, 2.541; 95\% confidence interval, 95\%CI, 1.284-5.028; $p=0.007$ ) [4]. Furthermore, the multivariate competing risk model showed that severe pneumonia cases (subdistribution hazards ratio, SDHR, 9.803; 95\%CI, 4.0623.67), leukocyte count more than $4000 / \mathrm{mm}^{3}$ (SDHR, 4.01; 95\%CI, 1.53-10.55), and interstitial abnormality on chest Xray $(\mathrm{SDHR}, 4.31 ; 95 \% \mathrm{CI}, 1.73-10.75)$ were related to the composite endpoint [4]. In this report, the leukocytosis might be attributed by neutrophilia, since lymphopenia developed simultaneously.

A bivariate Cox regression confirmed that neutrophilia was associated with both ARDS development (HR, 1.14; 95\%CI, $1.09-1.19 ; p<0.001)$ and progression to death (HR, 1.08; 95\%CI, 1.01-1.17; $p=0.03$ ) [12]. High neutrophil counts with activation of neutrophils possibly generate an immune response to fight with virus and contribute to the cytokine storm.

In patients with severe COVID-19, obvious lymphopenia emerged as ANC elevated concurrently. In the clinical reports mentioned above, the median lymphocyte count was 0.4 (IQR $0.2-0.8) \times 10^{9} / \mathrm{L}$ and $1.0(\mathrm{IQR} 0.7-1.1) \times 10^{9} / \mathrm{L}$ in ICU and non-ICU cases $(p=0.0041)$ in the Jin Yin-tan Hospital study and $0.8($ IQR $0.5-0.9) \times 10^{9} / \mathrm{L}$ and $0.9(\mathrm{IQR} 0.6-1.2) \times 10^{9} / \mathrm{L}$ in severe and common type patients $(p=0.03)$ in the Zhongnan Hospital [5, 7].

Then, a data of 61 cases with COVID-19 were analyzed and found that neutrophil-to-lymphocyte ratio (NLR) was a useful predictive factor for critical illness probability [28]. In this investigation, patients were divided into two groups based on the cutoff value of NLR (low risk, $<3.13$; high risk, $\geq 3.13$ ) and age ( $<50$ years or $\geq 50$ years) [28]. Stratification for severe disease incidence was performed according to age and NLR; it was found that in the population of age $\geq 50$ years, patients with high-risk NLR $(50 \%)$ were prone to develop severe illness than those with low risk NLR (9.1\%) $(p=$ 0.0195 ) [28]. Compared with the two typical scoring models, MuLBSTA (multilobular infiltration, lymphocytopenia, bacterial coinfection, smoking history, hypertension, and age) (0.762; 95\%CI, 0.585-0.938) and CURB-65 (confusion, urea, respiratory rate, blood pressure, age $\geq 65$ year $)(0.700 ; 95 \% \mathrm{CI}$, $0.505-0.896)$, NLR had a higher area under the curve $(0.849$; 95\%CI, 0.707-0.991), which suggests that NLR works better in early prediction of the incidence of critical conditions [28]. 


\section{Thrombocytopenia}

In the initial 41 COVID-19 cases reported by Jin Yin-tan Hospital, thrombocytopenia (platelet count $<100 \times 10^{9} / \mathrm{L}$ ) appeared in 5\% (2/40) of them [5]. Subsequently, a 99 cases report showed $12 \%$ of them developed thrombocytopenia [6]. A large sample size study of 1099 patients with COVID-19 demonstrated a higher incidence of thrombocytopenia (platelet count $<150 \times 10^{9} / \mathrm{L}$ ) of $36.2 \%$ [4]. Further analysis found that severe cases $(57.7 \%)$ exhibited an increased susceptibility to thrombocytopenia than non-severe one $(31.6 \%)(p<0.001)$, and the median platelet count in severe type was markedly lower than that in non-severe type: 137.5 (IQR $99.0-179.5) \times 10^{9} / \mathrm{L}$ vs 172.0 (IQR 139.0 $212.0) \times 10^{9} / \mathrm{L},(p<0.001)[4]$.

The investigation identified the lung as an organ with potential hematopoietic function and a primary site of terminal platelet production, which accounting for approximately $50 \%$ of the total platelet production [30]. On the basis of previous work proposing that the lungs are a reservoir for resident megakaryocytes and hematopoietic progenitor cells, suggesting thrombocytopenia could be caused by damage to the lungs [30]. Lung damage in COVID-19 could also induce the activation of RAS and cause abnormal functions of vascular endothelial cells and coagulation system, and platelet activation and aggregation, which might further increase consumption of platelet.

\section{Decline of hemoglobin}

Anemia was not a common laboratory finding of patients with SARS-CoV-2 infection, but the hemoglobin showed a descending tendency in fact. The first COVID-19 case in the USA showed a slight decrease in hemoglobin in illness day 6 and then recovered as the condition improved [10]. Hemoglobin was below the normal range in $51 \%$ of 99 patients with SARS-CoV-2 infection reported by Jin Yin-tan Hospital [6]. In 41 patients with COVID-19 pneumonia, the hemoglobin level of severe patients was lower, although the difference was not marked (122.0 g/L (111.0-128.0) vs $130.5 \mathrm{~g} / \mathrm{L}(120.0-140.0), p=0.20)$ [5]. In the study of 1099 patients with COVID-19, the hemoglobin level of $128.0 \mathrm{~g} / \mathrm{L}$ $(111.8-141.0)$ in severe group was lower than that of $135.0 \mathrm{~g} /$ L $(120.0-148.0)$ in non-severe one $(p<0.001)$ [4]. It is noteworthy that the reduction of hemoglobin was more pronounced in patients who reached composite endpoint (included admission to ICU, requirement of invasive ventilation and death) than in those who did not $(125.0 \mathrm{~g} / \mathrm{L}(105.0-140.0)$ vs $134.0 \mathrm{~g} / \mathrm{L}(120.0-148.0), p=0.012)$ [4]. In the report of Zhou et al., although there was no difference in the incidence of anemia, the hemoglobin of the patients with severe cases decreased more significantly (125.42 g/L (97-144) vs $145.24 \mathrm{~g} /$ $\mathrm{L}(111-162), p=0.002)[16]$.
Inflammatory changes caused by SARS-CoV-2 infection could interfere with erythropoiesis, resulting in a decrease in hemoglobin. The low incidence of anemia in COVID-19 may relate to the long life span of erythrocyte and the compensatory proliferation of erythrocyte induced by pneumoniaassociated hypoxia. For COVID-19, the reduced hemoglobin levels might be an indicator of disease progression, and it would be more worthy to focus on the decline of hemoglobin level, not on anemia.

\section{Other hematological abnormalities}

Thus far, human ACE2 has been confirmed as the receptor for the entry of SARS-CoV-2 into lower respiratory tract epithelial cells [21]. The physiological balance between ACE and ACE2 is likely disrupted by SRAS-CoV-2 infection, which results in the activation of RAS and abnormal functions of vascular endothelial cells and coagulation system [25]. The common chronic medical illness complicated with severe cases of COVID-19 induced diabetes, cardiovascular and cerebrovascular diseases, which are associated with vascular endothelial dysfunction [3-7].

D-dimer elevation and prolonged prothrombin time were observed in severe COVID-19 cases [5, 7]. In the early report of Jin Yin-tan Hospital, prothrombin time (12.2 s (IQR 11.213.4) vs $10.7 \mathrm{~s}$ (IQR 9.8-12.1), $p=0.012$ ) and $\mathrm{D}$-dimer level ( $2.4 \mathrm{mg} / \mathrm{L}$ (IQR $0.6-14.4$ ) vs $0.5 \mathrm{mg} / \mathrm{L}$ (IQR $0.3-0.8$ ), $p=$ 0.0042 ) on admission were higher in ICU cases than non-ICU cases [5]. The same outcome of D-dimer level was detected in Zhongnan Hospital that patients with critically condition had significantly elevated D-dimer level than common patients (414 mg/L (191-1324) vs $166 \mathrm{mg} / \mathrm{L}(101-285), p<0.001)$ [7]. The difference of prothrombin time between ICU and non-ICU patients was not proposed by the research of Zhongnan Hospital (13.2 s (12.3-14.5) vs 12.9 s (12.3 13.4), $p=0.37$ ) [7]. The latest study of 1099 cases with COVID-19 demonstrated that $46.4 \%$ of them had increased D-dimer levels $(\geq 0.5 \mathrm{mg} / \mathrm{L})$, and the severe patients were more prone to develop an elevation in D-dimer than nonsevere patients ( $59.6 \%$ vs $43.3 \%, p=0.003$ ); the rate of Ddimer elevation was as high as $69.4 \%$ in those who reached the composite endpoint [4].

\section{Conclusions}

COVID-19 is a new human infectious disease caused by a novel coronavirus SARS-CoV-2. Hematological abnormalities are not rare in COVID-19 patients including lymphopenia, neutrophilia, thrombocytopenia, and decline of hemoglobin. A conspicuous decline was observed in $\mathrm{CD}^{+}{ }^{+}$and $\mathrm{CD} 8^{+} \mathrm{T}$ lymphocytes. When the disease progresses to severe stage, lymphopenia continues to aggravate. Increased neotrophil 
count and neutrophil-to-lymphocyte ratio, and decreased hemoglobin concentration were identified as the risk factors of severe illness in patients with SARS-CoV-2 infection. The activation of monocyte-macrophage system aggravates the immune damage of the lung and other tissues, which leads to the increase of D-dimer, prothrombin time, and platelet consumption. The effects of SARS-CoV-2 on hematopoiesis are still poorly understood, which deserves further exploration.

Author contribution All authors have made substantive intellectual contributions to this study. Guangsheng He contributed to the study design and involved in drafting and revision of the article. Xiaoqing Liu contributed to literature research and data collection and is involved in drafting. Run Zhang contributed to the data collection, analysis, and revision of the article.

Funding information This study was supported by the State Administration of Traditional Chinese Medicine Industry Specialty (No. 201407001-4), the National Public Health Grand Research Foundation (No. 201202017), the Project Funded by the Priority Academic Program Development of Jiangsu Higher Education Institute (No. JX10231801), and the Project Funded by Jiangsu Provincial Special Program of Medical Science (No. BL2014086).

\section{Compliance with ethical standards}

Conflict of interest The authors declare that they have no conflict of interest.

Ethics approval Not applicable.

\section{References}

1. Li Q, Guan XH, Wu P, Wang XY, Zhou L, Tong YQ et al (2020) Early transmission dynamics in Wuhan, China, of novel coronavirus-infected pneumonia. N Engl J Med 382:1199-1207

2. WHO. Clinical management of severe acute respiratory infection when Novel coronavirus ( $\mathrm{nCoV}$ ) infection is suspected: interim guidance. Mar 13, 2020. https://www.who.int/publications-detail/ clinical-management-of-severe-acute-respiratory-infection-whennovel-coronavirus-(ncov)-infection-is-suspected

3. Xu XW, Wu XX, Jiang XG, Xu KJ, Ying LJ, Ma CL et al (2020) Clinical findings in a group of patients infected with the 2019 novel coronavirus (SARS-Cov-2) outside of Wuhan, China: retrospective case series. BMJ 368:m792

4. Guan WJ, Ni ZY, Hu Y, Liang WH, Ou CQ, He JX, et al. (2020) Clinical characteristics of coronavirus disease 2019 in China. N Engl J Med. https://doi.org/10.1056/NEJMoa2002032. [Online ahead of print]

5. Huang CL, Wang YM, Li XW, Ren LL, Zhao JP, Hu Y, Zhang L, Fan G, Xu J, Gu X, Cheng Z, Yu T, Xia J, Wei Y, Wu W, Xie X, Yin W, Li H, Liu M, Xiao Y, Gao H, Guo L, Xie J, Wang G, Jiang R, Gao Z, Jin Q, Wang J, Cao B (2020) Clinical features of patients infected with 2019 novel coronavirus in Wuhan, China. Lancet 395(10223):497-506

6. Chen NS, Zhou M, Dong X, Qu JM, Gong FY, Han Y, Qiu Y, Wang J, Liu Y, Wei Y, Xia J', Yu T, Zhang X, Zhang L (2020) Epidemiological and clinical characteristics of 99 cases of 2019 novel coronavirus pneumonia in Wuhan, China: a descriptive study. Lancet 395(10223):507-513
7. Wang DW, Hu B, Hu C, Zhu FF, Liu X, Zhang J, Wang B, Xiang H, Cheng Z, Xiong Y, Zhao Y, Li Y, Wang X, Peng Z (2020) Clinical characteristics of 138 hospitalized patients with 2019 novel coronavirus-infected pneumonia in Wuhan, China. JAMA 323(11):1061-1069

8. Lee N, Hui D, Wu A, Chan P, Cameron P, Joynt GM, Ahuja A, Yung MY, Leung CB, To KF, Lui SF, Szeto CC, Chung S, Sung JJY (2003) A major outbreak of severe acute respiratory syndrome in Hong Kong. N Engl J Med 348(20):1986-1994

9. Wong RS, Wu A, To KF, Lee N, Lam CW, Wong CK et al (2003) Haematological manifestations in patients with severe acute respiratory syndrome: retrospective analysis. BMJ 326(7403):13581362

10. Holshue ML, DeBolt C, Lindquist S, Lofy KH, Wiesman J, Bruce H, Spitters C, Ericson K, Wilkerson S, Tural A, Diaz G, Cohn A, Fox L, Patel A, Gerber SI, Kim L, Tong S, Lu X, Lindstrom S, Pallansch MA, Weldon WC, Biggs HM, Uyeki TM, Pillai SK, Washington State 2019-nCoV Case Investigation Team (2020) First case of 2019 novel coronavirus in the United States. N Engl J Med 382(10):929-936

11. Zhang JJ, Dong X, Cao YY, Yuan YD, Yang YB, Yan YQ et al (2020) Clinical characteristics of 140 patients infected with SARSCoV-2 in Wuhan, China. Allergy 00:1-12

12. Wu CM, Chen XY, Cai YP, Xia JA, Zhou X, Xu S, et al. (2020) Risk factors associated with acute respiratory distress syndrome and death in patients with coronavirus disease 2019 pneumonia in Wuhan, China. JAMA Intern Med. https://doi.org/10.1001/ jamainternmed.2020.0994. [Online ahead of print]

13. Guo LX, Wei D, Wu YR, Zhou M, Zhang XX, Li QY et al (2019) Clinical features predicting mortality risk in patients with viral pneumonia: the MuLBSTA Score. Front Microbiol 10:2752

14. Li TS, Qiu ZF, Han Y, Wang Z, Fan HW, Lv W et al (2003) Rapid loss of both CD4 (+) and CD8 (+) T lymphocyte subsets during the acute phase of severe acute respiratory syndrome. Chin Med J 116(7):985-987

15. Channappanavar R, Fehr AR, Vijay R, Mack M, Zhao JC, Meyerholz DK, Perlman S (2016) Dysregulated type I interferon and inflammatory monocyte-macrophage responses cause lethal pneumonia in SARS-CoV-infected mice. Cell Host Microbe 19(2):181-193

16. Zhou YG, Fu BQ, Zheng XH, Wang DS, Zhao CC, Qi YJ, et al. (2020) Aberrant pathogenic GM-CSF+ T cells and inflammatory CD14+CD16+ monocytes in severe pulmonary syndrome patients of a new coronavirus. bioRxiv. https://doi.org/10.1101/2020.02.12. 945576

17. Khaitan A, Unutmaz D (2011) Revisiting immune exhaustion during HIV infection. Curr HIV/AIDS Rep 8(1):4-11

18. Jin HT, Anderson AC, Tan WG, West EE, Ha SJ, Araki K, Freeman GJ, Kuchroo VK, Ahmed R (2010) Cooperation of Tim-3 and PD-1 in CD8 T-cell exhaustion during chronic viral infection. Proc Natl Acad Sci U S A 107(33):14733-14738

19. Xu Z, Shi L, Wang YJ, Zhang JY, Huang L, Zhang C, et al. (2020) Pathological findings of COVID-19 associated with acute respiratory distress syndrome. Lancet Respir Med. https://doi.org/10.1016/ S2213-2600(20)30085-0. [Online ahead of print]

20. Li W-H, Moore MJ, Vasilieva N, Sui J-H, Wong SK, Berne MA et al (2003) Angiotensin-converting enzyme 2 is a functional receptor for the SARS coronavirus. Nature 426(6965):450-454

21. Zhou P, Yang XL, Wang XG, Hu B, Zhang L, Zhang W, Si HR, Zhu Y, Li B, Huang CL, Chen HD, Chen J, Luo Y, Guo H, Jiang RD, Liu MQ, Chen Y, Shen XR, Wang X, Zheng XS, Zhao K, Chen QJ, Deng F, Liu LL, Yan B, Zhan FX, Wang YY, Xiao GF, Shi ZL (2020) A pneumonia outbreak associated with a new coronavirus of probable bat origin. Nature 579(7798):270-273

22. Paul M, Poyan MA, Kreutz R (2006) Physiology of local reninangiotensin systems. Physiol Rev 86(3):747-803 
23. Imai Y, Kuba K, Ohto-Nakanishi T, Penninger JM (2010) Angiotensin-converting enzyme 2 (ACE2) in disease pathogenesis. Circ J 74(3):405-410

24. Imai Y, Kuba K, Rao S, Huan Y, Guo F, Guan B, Yang P, Sarao R, Wada T, Leong-Poi H, Crackower MA, Fukamizu A, Hui CC, Hein L, Uhlig S, Slutsky AS, Jiang C, Penninger JM (2005) Angiotensinconverting enzyme 2 protects from severe acute lung failure. Nature 436(7047):112-116

25. Wu Y. (2020) Compensation of ACE2 function for possible clinical management of 2019-nCoV-induced acute lung injury. Virol Sin. https://doi.org/10.1007/s12250-020-00205-6. [Online ahead of print]

26. Haznedaroglu IC, Beyazit Y (2013) Local bone marrow reninangiotensin system in primitive, definitive and neoplastic haematopoiesis. Clin Sci (Lond) 124(5):307-323

27. Shen XZ, Okwan-duodu D, Blackwell WB, Ong FS, Janjulia T, Bernstein EA et al (2014) Myeloid expression of angiotensinconverting enzyme facilitates myeloid maturation and inhibits the development of myeloid-derived suppressor cells. Lab Investig 94(5):536-544

28. Liu J-Y, Liu Y, Xiang P, Pu L, Xiong H-F, Li C-S, et al. (2020) Neutrophil-to-lymphocyte ratio predicts severe illness patients with 2019 novel coronavirus in the early stage. medRxiv. https://doi.org/ 10.1101/2020.02.10.20021584

29. Fan BE, Chong VCL, Chan SSW, Lim GH, Lim KGE, Tan GB, et al. (2020) Hematologic parameters in patients with COVID-19 infection. Am J Hematol. https://doi.org/10.1002/ajh.25774. [Online ahead of print]

30. Lefrançais E, Ortiz-Muñoz G, Caudrillier A, Mallavia B, Liu FC, Sayah DM, Thornton EE, Headley MB, David T, Coughlin SR, Krummel MF, Leavitt AD, Passegué E, Looney MR (2017) The lung is a site of platelet biogenesis and a reservoir for haematopoietic progenitors. Nature 544(7648):105-109

Publisher's note Springer Nature remains neutral with regard to jurisdictional claims in published maps and institutional affiliations. 